\title{
A Pilot Study of the Tuning in to Kids Parenting Program in Iran for Reducing Preschool Children's Anxiety
}

\author{
Forough Edrissi $^{1,2} \cdot$ Sophie S. Havighurst ${ }^{3} \cdot$ Asma Aghebati $^{4} \cdot$ Mojtaba Habibi $^{5} \cdot$ Abbas Masjedi Arani $^{1}$
}

Published online: 15 April 2019

(c) The Author(s) 2019

\begin{abstract}
Objectives Tuning in to Kids (TIK) is a group parenting program that targets parent emotion socialization (emotional awareness and regulation, meta-emotion and emotion coaching skills) to improve children's functioning. The aim of this pilot study was to investigate the effectiveness of this program when used with parents of anxious preschool children.

Methods The study used a randomized controlled design. Fifty-six mothers of children who scored one standard deviation above the mean on the parent report of the Preschool Anxiety Scale (PAS) were selected from 358 families who expressed interest in participating in a parenting program. Selected participants were randomly assigned to intervention $(n=30)$ or control $(n=26)$ conditions. Participants in the intervention condition attended the 6 session TIK program followed by two booster sessions at monthly intervals thereafter. Post-intervention and 6- months later the PAS was re-administered to participants in both conditions.

Results Mixed Repeated Measure ANOVA analysis showed a significant difference between participants in the two conditions on parent-reported anxiety at post-test and 6-month follow-up. Clinical significance analyses showed $69 \%$ of the intervention group in comparison to $18 \%$ of the control group had parent-reported change into the normal range for anxiety scores. These changes remained stable at 6-month follow-up (60\% compared to $23 \%$ ).

Conclusion The study suggests that the TIK program shows preliminary effectiveness when used in Iran with preschool children with anxiety.
\end{abstract}

Keywords Tuning in to Kids $\cdot$ Anxiety $\cdot$ Preschool $\cdot$ Children $\cdot$ Mothers $\cdot$ Parenting program

Anxiety problems are the most prevalent emotional disorder in children and adolescents (Rapee et al. 2009) with prevalence rates in pre-school children reportedly ranging from $1.5 \%$ (Wichstrom et al. 2012) to $22.2 \%$ (Paulus et al. 2015)

Forough Edrissi

forough.edrissi@gmail.com

1 Department of Clinical Psychology, Shahid Beheshti University of Medical Sciences, School of medicine, Tehran, Iran

2 Talegani Educational Hospital, Tabnak St., Velenjak Region, Chamran High Way, Tehran 1985711151, Iran

3 Mindful: Centre for Training and Research in Developmental Health, University of Melbourne, Melbourne, Australia

4 Department of Clinical Psychology, School of Behavioral Sciences and Mental Health (Tehran Institute of Psychiatry), Iran University of Medical Sciences, Tehran, Iran

5 Department of Health Psychology, School of Behavioral Sciences and Mental Health (Tehran Institute of Psychiatry), Iran University of Medical Sciences, Tehran, Iran depending on the country. Anxiety in preschool children differs from older children and adults, with preschoolers being more likely to show anxiety through behaviors such as avoidance, crying, anger, freezing, or clinging rather than expressing subjective feelings of fear or anxieties about specific stimuli (e.g., phobias) (Egger and Angold 2006; Hirshfeld-Becker et al. 2010). Anxious preschoolers are more likely to have other anxiety disorders, depression (Bufferd et al. 2011), Attention Deficit Hyperactivity Disorder (ADHD) (Lavigne et al. 2009) and Oppositional Defiant Disorder (ODD) (Martin et al. 2017). Anxiety is often pervasive causing significant interference in many aspects of development including education, social relationships, and continuing through to adulthood by adversely impacting occupational and social aspects of life (Wood et al. 2003). In addition, anxiety is associated with considerable economic cost (Farrell and Barrett 2007). In Iran, childhood anxiety occurs at a similar rate to Western countries, with between 7 and 10\% prevalence rates having 
been found in preschool children (Davoudi et al. 2014; Pourhossein et al. 2015).

Given that children with early anxiety symptoms are at risk for anxiety disorders and poorer general functioning as they get older (Bufferd et al. 2011), early identification and preventive interventions are integral for altering this life trajectory. A number of cognitive-behavior therapy (CBT) interventions and prevention programs have been developed to this end including Cool Little Kids (Rapee et al. 2005), REACH for RESILIENCE (Dadds and Roth 2008) and FUN FRIENDS (Barrett 2007), all aimed at preschool children. Although evaluations of these programs are promising, studies of the efficacy of CBT programs for anxiety indicate that $40-50 \%$ of anxious children still suffer impairment from anxiety after receiving the intervention (Hannesdottir and Ollendick 2007). Determining what aspects of interventions are effective and what other components are necessary to reduce child anxiety is an important theoretical and empirical question. One critical review of childhood anxiety treatment found only eight intervention trials with at least 2-year follow-up data; of these, outcomes were promising in the use of CBT but confounding factors such as normal maturation could not be ruled out as the reason for changes (Nevo and Manassis 2009). Recent empirical research has shown that difficulties with emotion regulation are a key component of childhood anxiety disorders (Carthy et al. 2010; Suveg and Zeman 2004) and a recent meta-analysis demonstrated the contributing role of emotion regulation in child anxiety (Mathews et al. 2016). Emotion regulation can be defined as "the extrinsic and intrinsic processes responsible for monitoring, evaluating, and modifying emotional reactions, especially their intensive and temporal features, to accomplish one's goals" (Thompson 1994: pp. 27-28). Suveg and Zeman (2004) found that children with anxiety were more likely to have intense negative emotions and to have difficulty managing these. Typically, however, CBT interventions do not focus on the emotion regulation skills of anxious children and a number of researchers have emphasized that this appears to be an important direction for improving anxiety treatment (Hannesdottir and Ollendick 2007; Mathews et al. 2016).

One avenue via which to target children's emotion regulation and other aspects of emotion competence, or how children express emotions and their knowledge of emotions, is by looking at how parenting influences this aspect of children's development (Denham 1998). This process, known as emotion socialization, includes parents' reaction to children's emotions, their discussion/coaching of their children's emotions, and how they express emotions that have all been found to influence children's emotion competence (Eisenberg et al. 1998). Parents of anxious children have been found to be more dismissive of children's emotions and often model or express a lot of anxiety themselves (Suveg et al. 2005). In Iran, there is no specificresearch on parents' emotion socialization practices with anxious preschool children. Research has, however, found that Iranian parents are more likely to use an authoritarian parenting style (Shahaeian et al. 2014) which may be consistent with emotionally disapproving parenting outlined by Gottman et al. (1996). Also, in a comparative study between Iran and Germany, findings indicated that Iranian parents reported a more frequent use of laxness as a parenting strategy when compared to German parents (Tahmouresi et al. 2017).

One parenting program that targets emotion regulation via parent emotion socialization and has established evidence is the Tuning in to Kids (TIK) program (Havighurst and Harley 2007). TIK aims to improve parent emotion coaching, or responding by scaffolding and teaching children to learn about emotions, and parents' own emotion awareness and regulation while also reducing their emotionally dismissive/harsh parenting. While TIK has been found effective in improving parenting as well as reducing child externalizing behavior problems (Havighurst et al. 2013; Wilson et al. 2012), there is only one preliminary study of the program that has examined its impact on anxiety difficulties in preschool children. In a non-peer reviewed study, Hasen (2015) evaluated TIK in the prevention (with a community sample) and treatment (with a small clinical sample) of anxiety in preschool children and found preliminary support for the program in reducing children's anxiety problems. A version of the program with early adolescents (Tuning in to Teens) has also been found to reduce internalizing problems in a community sample (Kehoe et al. 2014). These studies provide justification for a study to replicate these findings with a sample of children with clinical levels of anxiety in a country other than Australia.

Because TIK is a relatively new program and there is minimal evidence so far of the benefits of the program with internalizing disorders, the aim of the present study was to investigate the effectiveness of TIK when used in Iran with a sample of preschool children identified with anxiety problems. The research question examined whether, relative to control participants, the TIK parenting program would reduce anxiety in a sample of preschool children identified as having high levels of anxiety.

\section{Method}

\section{Participants}

The sample comprised 45 children ( $58 \%$ boys; $42 \%$ girls) aged between 4 and 6 years of age $\left(M_{\text {age }}=4.4\right.$ years, 
$S D=.75)$. The study included the primary caregiving parent; all were mothers $\left(M_{\text {age }}=34.0\right.$ years, $\left.S D=4.52\right)$. The mean age of the mothers was 33 years old, while the mean age of the fathers was 37 years old. Sixty-four percent of mothers had one child and the rest had two children. Most mothers $(71 \%)$ had a bachelor's degree and $29 \%$ had a high school diploma. Eighty-two percent of mothers were not in paid work. Family incomes ranged from very low to moderate for Iran: less than $\$ 7200$ USD annually (42\%), above $\$ 7200$ USD annually (58\%). In 2015, the Statistical Center of Iran (2017) reported Iran's average annual total income per urban household was approximately $\$ 8554$ USD. Chisquare tests revealed there were no significant differences in demographic variables between the intervention and control participants.

\section{Procedure}

The present study was a randomized controlled trial (RCT) with participants randomized into intervention or control conditions. Mothers of preschool children (4-6 years) attending kindergartens and Neighborhood Houses in Tehran in 2015-2016 were invited to be considered for participation in a parenting program. Neighborhood Houses are governed by volunteer committees and the local municipality, and function to bring people together to connect, learn and contribute in their local community through providing social, educational, recreational activities. The most common activities which generally run at low or no cost to participants are health and wellbeing activities including parenting. In order to recruit from a range of areas using a cluster sampling method, Tehran was divided into five regions (lower to middle socioeconomic class regions of north, south, east, west and central Tehran); 11 centers were approached and 70\% (two kindergartens and six neighborhood houses) were invited and agreed to participate in the research. These centers formed the main clusters and were randomly assigned into intervention $(N=4)$ or control $(N=2)$ centers. Posters were put up in centers and flyers were sent home to the parents of every child inviting them to participate in the research. In addition, kindergarten teachers were asked to refer the parents of children who were having difficulties with anxiety or problems with separation. Expressions of interest were received from 358 primary caregiving parents and all were then asked to complete the Preschool Anxiety Scale (PAS) (Spence et al. 2001). Sixty-five children were rated by their mothers as scoring at least one SD above the mean for the PAS (PAS $\geq$ $35,+1$ SD above Mean, $t=60$ ) and met inclusion and not exclusion criteria. The inclusion criteria for the study were: scoring one SD above the mean for the PAS, a minimum of completing a high school diploma for mothers in order to understand the questionnaires and read the program handouts, participants' agreeing to participate in the study and giving informed written consent. Exclusion criteria were diagnosis of any previous mental health disorder in the child other than anxiety, depression, diagnosis of any psychiatric disorder that was caused by a medical condition or any medical condition that might interfere with the treatment for the child; a child being in therapy in another study; a mother receiving psychotherapy during the study; a child receiving psychotropic medication, changing medicine or receiving treatment for psychological problems one month before the study began. The final sample consisted of 56 participants who met these conditions: they were then randomly assigned to intervention $(N=30)$ or control $(N=26)$ conditions. Once allocated (but before mothers were notified of which condition they had been assigned), mothers in both conditions were asked to complete baseline assessment questionnaires. Then those allocated to the intervention condition attended a 6 -session TIK group parenting program followed by two booster sessions at one monthly intervals afterwards. Post-intervention and 6-months follow-up questionnaires were given to all participants (control participants at the same time intervals) with $80 \%$ (intervention $=23$; waitlist control $=22$ ) returned at postintervention and all who completed the questionnaires in time 2 returning questionnaires at 6-month follow-up. After the final follow-up assessment, control participants were offered the TIK parenting program. The study adhered to ethical principles and was approved by the ethics committee of Shahid Beheshti University of Medical Sciences. The participants were informed of the aims and process of the study and all gave informed consent.

\section{Intervention: Tuning in to Kids (TIK)}

TIK (Havighurst and Harley 2007) is a structured, six-session, 2-h weekly group parenting program, with two followup "booster" sessions recommended to reinforce skills learned. Parents are taught the five steps of emotion coaching (Gottman et al. 1998): (a) become aware of the child's emotion, especially if it is at a lower intensity; (b) view the child's emotion as an opportunity for intimacy and teaching; (c) communicate understanding and acceptance of the emotion; (d) help the child to use words to describe how they feel; and (e) if necessary, assist them with problemsolving (while setting limits). Different exercises in the program teach these five steps, with content specified as core, optional, or home activities. Tuning in to Kids focuses on parental emotion socialization practices with the expectation that improving these will lead to improvements in children's emotional competence and behavior. Parents learn skills in their own emotion awareness and regulation, 
explore their meta-emotion philosophy (their beliefs and reactions to emotions) and consider how their family of origin experiences have shaped their parenting. Activities include psycho-education, watching DVD examples of emotion coaching and dismissing, use of handout materials, practice exercises, role plays, and group discussion.

TIK sessions were held in four Neighborhood Houses in Tehran in the morning facilitated by the first author and one co-facilitator (both $\mathrm{PhD}$ students in clinical psychology). Both facilitators were trained in a 3-day training by one of the TIK program authors and received supervision throughout the intervention delivery to ensure they adhered to the structured program manual and to address issues that arose in delivery. Fidelity checklists were completed after each session and $100 \%$ of core content was delivered.

Four intervention groups were conducted and averaged seven mothers in each group (range 5-8). Of the 30 mothers in the intervention condition, $19(63.3 \%)$ completed four to six sessions of the program, four (13\%) attended three sessions, seven $(23.3 \%)$ attended one session. There were no significant differences in group characteristics or child anxiety scores at baseline between participants who attended 4-6 sessions versus those who attended only one session. If mothers were unable to attend, they were called by the facilitator and were given information about the missed sessions.

\section{Measures}

\section{The Preschool Anxiety Scale (PAS)}

The PAS is a 28 -item parent-report scale that consists of five subscales of anxiety matching the DSM-IV classifications: separation anxiety, social anxiety, physical injury fears, obsessive compulsive and generalized anxiety. Higher total anxiety scores (range: 0-112) indicate severe problems. Psychometric characteristics of this scale indicate it has good internal consistency: Cronbach alphas above 0.70 have been reported for all subscales except the obsessivecompulsive disorder subscale. In a study of the psychometric properties of the translated version of the PAS in Iran, all subscales of the PAS (with the exception of the OCD subscale) displayed moderate to high internal consistency (0.64-0.76) and high (0.73-0.82) correlations in test-retest (Ghanbari et al. 2014). Validity evaluations also showed positive results including face validity that was confirmed by clinicians. Correlations of the total PAS score and all subscales of the PAS with the Conner's Behavior Rating Scale ranged from moderate to high (0.41 to 0.67) suggesting the measure has adequate psychometric properties (Ghanbari et al. 2014). In the current study the Cronbach alphas was $.65, .72$ and .71 for PAS Total at preintervention, post-intervention and 6-month follow up respectively. There was also moderate to high internal consistency for all subscales (.47 to .61) at pre-intervention, (.41 to .62) at post-intervention and (.42-.61) at follow-up (with the exception of the Separation Anxiety subscale that was $.40, .37, .40$ at each time point, respectively).

\section{Results}

Sample characteristics were assessed for comparability between intervention and control condition at Time 1. There was no significant difference in mean age of mothers $(t(43)$ $=0.85, p=.40)$ using independent $t$-test, nor in child age $(t$ $(43)=-1.50, p=.15)$. Participants in both conditions were also matched on the PAS $(t \quad(43)=-1.86$, $p=.07$ ). Descriptive statistics (means and standard deviations) of PAS and subscales are presented in Table 1. Before analysis, statistical assumptions were reviewed. The results of a Kolmogorov-Smirnov test for anxiety at pre-test, posttest and follow-up, respectively, $(p=.58, p=.71, p=.74)$ were computed for intervention and control conditions and showed that anxiety was distributed normally in both groups. The assumption of homogeneity of variance was assessed using Levene's test. The significance level of the test in measuring anxiety at pre-intervention, postintervention and 6-month follow-up respectively was greater than $p=.05(p>.05)(p=.98, p=.29, p=.78)$ and it can be concluded with $95 \%$ confidence that the homogeneity of variance was violated. Mauchly's Test of Sphericity was then used to examine equality of variancecovariance matrices. The results showed that the sphericity assumption was not established $\left(p=.001<.05, \chi^{2}=24.38\right)$ thus because of the Epsilon quantity $(\varepsilon>75)$, a Huynh-Feldt correction was used.

Repeated measures ANOVAs were conducted to test differences between the intervention and control condition for PAS and the subscales. Participant condition (intervention vs control) was used as a between-subject variable, and time (in pre-intervention, post-intervention, and follow-up) as a within-subject variable. This enabled changes to be examined for all (within-subject analysis over time) as well as comparing the two conditions (between-subject analyses across conditions) enabling examination of whether changes were particular to those in the TIK intervention. Following ANOVA, reliability and clinically significant change analyses were conducted.

Table 1 summarizes the results of repeated measures ANOVAs for the PAS Total and the subscales. Results of repeated measures ANOVAs for between-group effects indicated that for the PAS Total there was a significant difference between the two conditions $(F(1,43)=13.01 ; p$ $=.001)$, that showed that at 6-month follow-up. Those mothers who attended the TIK intervention had children 


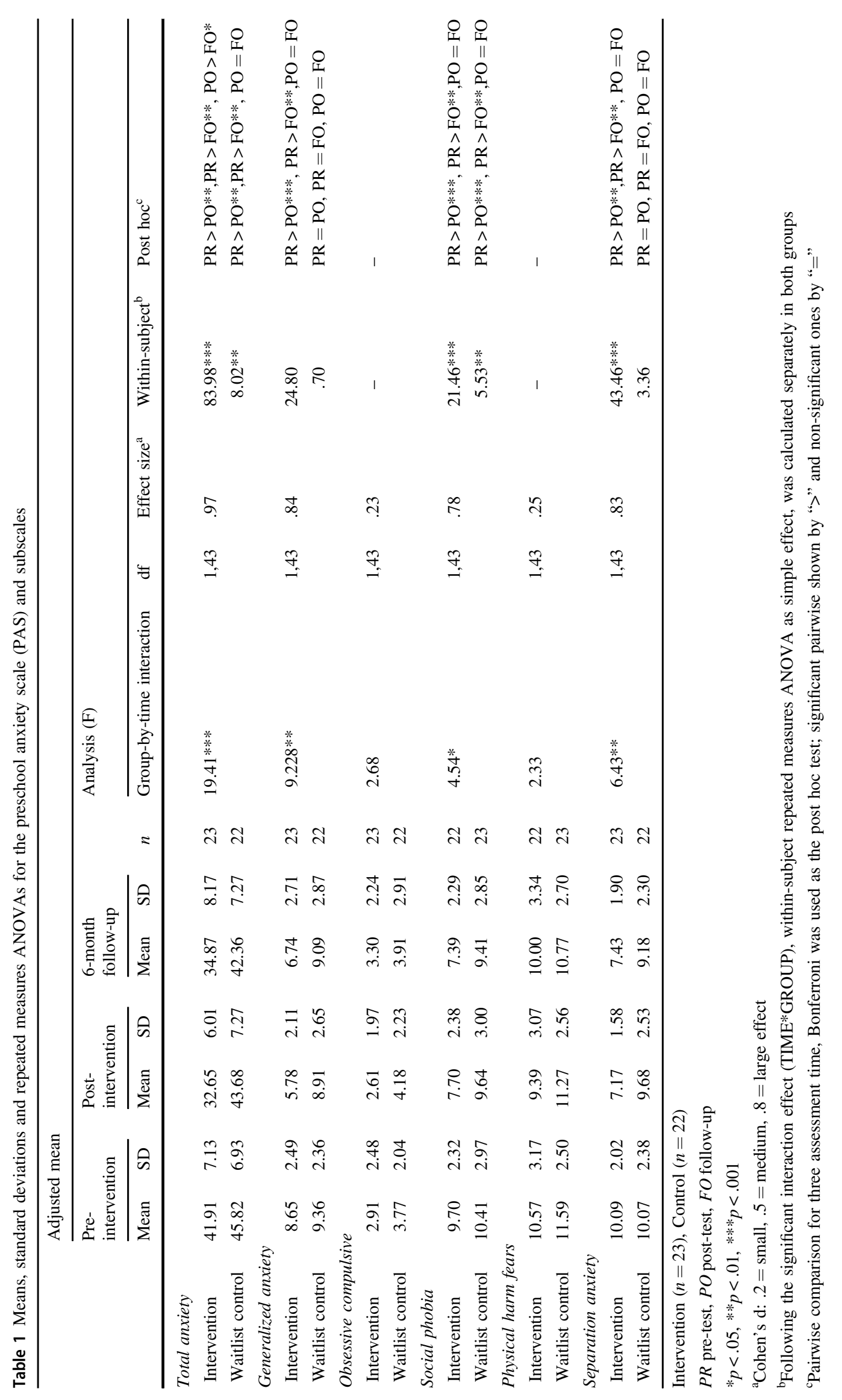


with significantly lower anxiety while those in the control condition did not change. Furthermore, partial eta squared $\left(\eta^{2}\right)$ was 0.23 , which means that $23 \%$ of between-group changes might be explained by the intervention; the significance of between-subject differences was confirmed by within-subject interaction effects (Time*Group) $(p<.01)$. Then, a within-subject effect (Time) using repeated measures ANOVA was performed with those in both conditions. Bonferroni post hoc tests demonstrated that anxiety scores decreased immediately post intervention $(M=32.65$, $S D=6.01)$. A significant decrease in scores was evident from pre-intervention to 6-month follow-up $(p<.01)$. In addition, an independent t-test was conducted to compare anxiety across the two conditions. There was a significant difference in the scores for anxiety at post intervention $(t$ $(43)=-5.53, p<.01)$ and 6-month follow-up $(t(43)=$ $-3.10, p<.01)$. These results suggest that severity of child anxiety significantly decreased from pre- to postintervention and this improvement was maintained at 6month follow-up for those in the intervention condition. The control condition also improved over the assessment period but there was a greater reduction in anxiety for those in the intervention condition (reduction in a mean score from 42 to 33) compared to the control condition (where change was from a mean score 46-44).

Repeated measures ANOVAs were also conducted to examine the impact of the intervention on the five subscales of the PAS, and these analyses indicated that there were significant between-group interaction effects for Time*Group and a main effect for Time for the Generalized Anxiety (GA), Separation Anxiety (SA) and Social Phobia (SP) subscales. Therefore, it can be concluded with $95 \%$ confidence that there was a significant difference between the two groups regarding the effectiveness of the TIK intervention in reducing parent-reported GA, SA and SP. The subscales of Obsessive Compulsive and Physical Harm fears did not significantly decrease.

Analyses were conducted to see if changes were clinically significant at post-intervention and follow up. In psychological interventions, individuals' changes may be statistically significant yet clinically insignificant; however, it is possible to establish whether an intervention has had a significant impact when participants' scores are lower than the identified clinical cut-off point. The cut-off for the PAS is 35 or greater, which is one standard deviation above the mean score for the measures. All participants in the study had a score at pre-intervention above this cut off (it was one of the study inclusion criteria). At post-intervention 16 children $(69 \%)$ in the Intervention condition were reported by their parents to be in the normal range, while at 6-month follow-up 14 children $(60 \%)$ were reported in the normal range. In contrast in the control condition, four children $(18 \%)$ were reported by their parents to have reduced to the normal range at the post-intervention, while at follow-up five children $(23 \%)$ had scores reported in the normal range.

The Reliability Change Index (RCI) has also been used as a tool for measuring clinically meaningful change in research (Jacobson and Truax 1991). Typically, for a change to be significant, the RCI value must be higher than 1.96. In the current study, the RCI at post-intervention was calculated as 2.16 for the PAS based on the Jacobson and Traux formula (Jacobson and Truax 1991). As this number is higher than 1.96 , it can be said with $95 \%$ confidence that the parent-reported shift or change from pre-intervention to post-intervention score was not considered a coincidence but was a consistent and real change. The RCI index was calculated as 1.43 at follow-up, however, this showed that the changes were no longer quite as strong.

Intention to treat analyses were conducted with preintervention data also used at post-intervention and 6-month follow up for those participants with missing data at these follow-up points (this assumes no change for these participants). All results held at $p<.05$, except for Separation Anxiety $(p=.11)$ which became non-significant.

\section{Discussion}

TIK is a group-based program that targets parents' skills in understanding and responding to emotions in themselves and their children. The program teaches emotion coaching and aims to reduce emotionally dismissive parenting while also enhancing parents' own skills in regulating their emotions. Previous research on the program has not been conducted in non-Western countries and only preliminary evidence exists as to whether the program is effective for reducing child anxiety. The aim of this pilot study was to examine the effectiveness of TIK in Iran for reducing anxiety in preschool children at risk for anxiety disorders. The results of the current study suggest that the TIK program has led to significant reductions in parent reports of their preschoolers' anxiety for those in the intervention condition but not for those in the control condition. These results are consistent with previous preliminary findings on the impact of TIK on child anxiety by Hasen (2015) in Australia, where the TIK program resulted in a significant decrease in anxiety when delivered as a universal (for all) and an indicated (those with elevated anxiety) prevention program. The current study extends this work and suggests that an emotion socialization parenting intervention appears to be effective in reducing parent-reported child anxiety in Iran providing evidence for the theoretical links between these constructs (Suveg et al. 2009). These findings also extend the evidence-base of what works as an intervention for child anxiety. Other studies have also found that interventions that incorporate cognitive-behavioral skills as well 
as focus on emotion regulation can be efficacious in treating anxiety disorders in middle childhood (Suveg et al. 2018; Suveg et al. 2009).

Examining the clinical and reliable significance of changes in the intervention participants adds further strength to the study findings. At post-intervention, $69 \%$ of the intervention group in comparison to $18 \%$ of the control group had moved into the normal range for anxiety as reported by parents. These results remained stable at followup (60\% compared to $23 \%$ ) but were no longer reliably significant on the RCI. These findings also suggest that children with higher levels of anxiety at pre-intervention may have needed more sessions to make treatment effects beneficial. Subscale analyses showed that parents reported changes in areas where anxiety is often found in the preschool years-Separation Anxiety and Social Phobia (Egger ands Angold 2006), while Generalized Anxiety was also reported to have reduced. Changes in Obsessive Compulsive or Physical Harm fears symptoms were not found; however, this was not unexpected given the low rates of occurrence in the preschool years (Marakovitz et al. 2011; Douglass et al. 1995).

This study had a number of limitations including that outcomes were based on parent report which is subject to expectancy bias. It is possible that mothers reported changes in their ratings of the children's anxiety as a result of their participation in the program, rather than their children actually were less anxious. Reports from kindergarten teachers or observation measures would have provided further verification of the parent-reported changes. However, given similar changes have been found in other TIK research trials where observation and teacher report measures verified the parent-reported changes, the findings here may be a representation of actual change in children's anxiety.

In terms of the clinical application of these findings for future studies, a treatment trial using descriptive case studies would give greater information about how TIK can be used clinically in parents of at-risk children. Further exploration of these themes in Iranian parents would provide clinicians with valuable and more accurate insight into what might be happening for Iranian parents of anxious children. Finally, future research should incorporate longerterm follow-up and measures of other variables considered integral to the prevention of anxiety symptoms in young children, such as parenting behavior and parent-child interaction processes.

This pilot study examined the effectiveness of the Tuning in to Kids (TIK) program with a sample of 4-6-year-old children with anxiety problems, compared to waitlist controls. Despite parents in both groups reporting decreased anxiety in their children at post-intervention and 6-months follow-up, only parents in the TIK condition reported significantly reduced child anxiety. This study provides preliminary support for the use of an emotion-focused group parenting program as an intervention for preventing and reducing preschool children's anxiety problems. These findings are also in a non-Western sample, providing support for the use of an emotion socialization intervention in an Iranian cultural setting. Further research using observation and teacher reported outcomes measures delivered across a range of families in Iran will be an important next step.

\section{Compliance with Ethical Standards}

Conflict of Interest The authors disclose a conflict of interest in that the last author, Havighurst, may benefit from positive reports about the Tuning in to Kids program.

Publisher's note: Springer Nature remains neutral with regard to jurisdictional claims in published maps and institutional affiliations.

Open Access This article is distributed under the terms of the Creative Commons Attribution 4.0 International License (http://crea tivecommons.org/licenses/by/4.0/), which permits use, duplication, adaptation, distribution, and reproduction in any medium or format, as long as you give appropriate credit to the original author(s) and the source, provide a link to the Creative Commons license, and indicate if changes were made.

\section{References}

Barrett, P. M. (2007). Fun Friends. The Teaching and Training Manual for Group Leaders. Brisbane: Fun Friends Publishing.

Bufferd, S. J., Dougherty, L. R., Carlson, G. A., \& Klein, D. N. (2011). Parent-reported mental health in preschoolers: findings using a diagnostic interview. Comprehensive Psychiatry, 52(4), 359-369. https://doi.org/10.1016/j.comppsych.2010.08.006.

Carthy, T., Horesh, N., Apter, A., \& Gross, J. J. (2010). Patterns of emotional reactivity and regulation in children with anxiety disorders. Journal of Psychopathology and Behavioral Assessment, 32(1), 23-36. https://doi.org/10.1007/s10862-009-9167-8.

Dadds, M. R., \& Roth, J. H. (2008). Prevention of anxiety disorders: results of a universal trial with young children. Journal of Child and Family Studies, 17(3), 320-335. https://doi.org/10.1007/ s10826-007-9144-3.

Davoudi, I., Poloi-Shaporabadi, F., \& Bassak-Nejad, S. (2014). Efficacy of family anxiety management training with mothers of anxious preschool children. Zahedan Journal of Research in Medical Sciences, 16(5), 45-49.

Denham, S. A. (1998). Emotional development in young children. New York, NY: Guilford Press.

Douglass, H. M., Moffitt, T. E., Dar, R., McGee, R., \& Silva, P. (1995). Obsessive-compulsive disorder in a birth cohort of 18-year-olds: prevalence and predictors. Journal of the American Academy of Child \& Adolescent Psychiatry, 34(11), 1424-1431.

Egger, H. L., \& Angold, A. (2006). Common emotional and behavioral disorders in preschool children: presentation, nosology, and epidemiology. Journal of Child Psychology and Psychiatry, 47(3-4), 313-337.

Eisenberg, N., Cumberland, A., \& Spinrad, T. L. (1998). Parental socialization of emotion. Psychological Inquiry, 9(4), 241-273. 
Farrell, L. J., \& Barrett, P. M. (2007). Prevention of childhood emotional disorders: reducing the burden of suffering associated with anxiety and depression. Child and Adolescent Mental Health, 12 (2), 58-65. https://doi.org/10.1111/j.1475-3588.2006.00430.x.

Ghanbari, S., Khodapanahi, M. K., Mazaheri, M. A., \& Gholami Lavasani, M. (2014). The effectiveness of attachment based parent training on increasing maternal caregiving quality in preschool anxious children. Journal of Family Research, 9(4), 407-426.

Gottman, J., Declaire, J., \& Goleman, D. (1998). The heart of parenting: Raising an emotionally intelligent child. London: Bloomsbury.

Gottman, J. M., Katz, L. F., \& Hooven, C. (1996). Parental metaemotion philosophy and the emotional life of families: Theoretical models and preliminary data. Journal of Family Psychology, 10(3), 243

Hannesdottir, D. K., \& Ollendick, T. H. (2007). The role of emotion regulation in the treatment of child anxiety disorders. Clinical Child and Family Psychology Review, 10(3), 275-293. https:// doi.org/10.1007/s10567-007-0024-6.

Hasen, G. (2015). Are you feeling worried? Childhood anxiety: emotional competence and parent emotion socialisation $(\mathrm{PhD}$ thesis). Melbourne: Melbourne School of Psychological Sciences. http://hdl.handle.net/11343/51090.

Havighurst, S. S., \& Harley, A. (2007). Tuning in to Kids: Emotionally intelligent parenting program manual. Melbourne: University of Melbourne.

Havighurst, S. S., Wilson, K. R., Harley, A. E., Kehoe, C., Efron, D., \& Prior, M. R. (2013). "Tuning into Kids": reducing young children's behavior problems using an emotion coaching parenting program. Child Psychiatry and Human Development, 44 (2), 247-264.

Hirshfeld-Becker, D. R., Masek, B., Henin, A., Blakely, L. R., Pollock-Wurman, R. A., McQuade, J., \& Biederman, J. (2010). Cognitive behavioral therapy for 4- to 7-year-old children with anxiety disorders: a randomized clinical trial. Journal of Consulting and Clinical Psychology, 78(4), 498-510.

Jacobson, N. S., \& Truax, P. (1991). Clinical significance: a statistical approach to defining meaningful change in psychotherapy research. Journal of Consulting and Clinical Psychology, 59(1), 12-19.

Kehoe, C. E., Havighurst, S. S., \& Harley, A. E. (2014). Tuning in to teens: improving parent emotion socialization to reduce youth internalizing difficulties. Social Development, 23(2), 413-431.

Lavigne, J. V., Lebailly, S. A., Hopkins, J., Gouze, K. R., \& Binns, H. J. (2009). The prevalence of ADHD, ODD, depression, and anxiety in a community sample of 4-year-olds. Journal of Clinical Child Adolescent Psychology, 38(3), 315-328.

Marakovitz, S. E., Wagmiller, R. L., Mian, N. D., Briggs-Gowan, M. J., \& Carter, A. S. (2011). Lost toy? Monsters under the bed? Contributions of temperament and family factors to early internalizing problems in boys and girls. Journal of Clinical Child \& Adolescent Psychology, 40(2), 233-244.

Martin, V., Granero, R., Domenech, J. M., \& Ezpeleta, L. (2017). Factors related to the comorbidity between oppositional defiant disorder and anxiety disorders in preschool children. Anxiety Stress Coping, 30(2), 228-242. https://doi.org/10.1080/ 10615806.2016.1228897.

Mathews, B. L., Koehn, A. J., Abtahi, M. M., \& Kerns, K. A. (2016). Emotional competence and anxiety in childhood and adolescence: a meta-analytic review. Clinical Child and Family Psychology Review, 19(2), 162-184. https://doi.org/10.1007/s10567-0160204-3.

Nevo, G. A., \& Manassis, K. (2009). Outcomes for treated anxious children: a critical review of long-term-follow-up studies. Depression and Anxiety, 26(7), 650-660.
Paulus, F. W., Backes, A., Sander, C. S., Weber, M., \& von Gontard, A. (2015). Anxiety disorders and behavioral inhibition in preschool children: a population-based study. Child Psychiatry and Human Development, 46(1), 150-157.

Pourhossein, R., Habibi, M., Ashoori, A., Ghanbari, N., Riahi, Y., \& Ghodrati, S. (2015). Prevalence of behavioral disorders among preschool children. Journal of Fundamentals of Mental Health, 17(5), 234-239.

Rapee, R. M., Kennedy, S., Ingram, M., Edwards, S., \& Sweeney, L. (2005). Prevention and early intervention of anxiety disorders in inhibited preschool children. Journal of Consulting and Clinical Psychology, 73(3), 488-497.

Rapee, R. M., Schniering, C. A., \& Hudson, J. L. (2009). Anxiety disorders during childhood and adolescence: origins and treatment. Annual Review of Clinical Psychology, 5, 311-341.

Shahaeian, A., Nielsen, M., Peterson, C. C., \& Slaughter, V. (2014). Cultural and family influences on children's theory of mind development: a comparison of Australian and Iranian school-age children. Journal of Cross-Cultural Psychology, 45(4), 555-568.

Spence, S. H., Rapee, R., McDonald, C., \& Ingram, M. (2001). The structure of anxiety symptoms among preschoolers. Behaviour Research and Therapy, 39(11), 1293-1316. https://doi.org/10. 1016/S0005-7967(00)00098-X.

Statistical Center of Iran. (2017). Average Annual Income of an Urban/Rural Household. https://www.amar.org.ir/english/Sta tistics-by-Topic/Household-Expenditure-and-Income\#2220529time-series.

Suveg, C., Jones, A., Davis, M., Jacob, M. L., Morelen, D., Thomassin, K., \& Whitehead, M. (2018). Emotion-focused cognitivebehavioral therapy for youth with anxiety disorders: a randomized trial. Journal of Abnormal Child Psychology, 46(3), $569-580$.

Suveg, C., Sood, E., Comer, J. S., \& Kendall, P. C. (2009). Changes in emotion regulation following cognitive-behavioral therapy for anxious youth. Journal of Clinical Child \& Adolescent Psychology, 38(3), 390-401.

Suveg, C., \& Zeman, J. (2004). Emotion regulation in children with anxiety disorders. Journal of Clinical Child \& Adolescent Psychology, 33(4), 750-759. https://doi.org/10.1207/ s15374424jecp3304_10.

Suveg, C., Zeman, J., Flannery-Schroeder, E., \& Cassano, M. (2005). Emotion socialization in families of children with an anxiety disorder. Journal of Abnormal Child Psychology, 33(2), 145-155.

Tahmouresi, N., Schmitz, J., Bender, C., \& Tuschen-Caffier, B. (2017). The impact of culture on parenting and psychopathology in children: a comparative study between Iran and Germany. Iranian Journal of Psychiatry and Behavioral Sciences, 11(1), $1-8$.

Thompson, R. A. (1994). Emotion regulation: a theme in search of definition. Monographs of the society for research in child development, 59(2-3), 25-52.

Wichstrom, L., Berg-Nielsen, T. S., Angold, A., Egger, H. L., Solheim, E., \& Sveen, T. H. (2012). Prevalence of psychiatric disorders in preschoolers. Journal of Child Psychology and Psychiatry, 53(6), 695-705.

Wilson, K. R., Havighurst, S. S., \& Harley, A. E. (2012). Tuning in to Kids: an effectiveness trial of a parenting program targeting emotion socialization of preschoolers. Journal of Family Psychology, 26(1), 56-65.

Wood, J. J., McLeod, B. D., Sigman, M., Hwang, W. C., \& Chu, B. C. (2003). Parenting and childhood anxiety: theory, empirical findings, and future directions. Journal of Child Psychology and Psychiatry, 44(1), 134-151. 